\title{
Long-Term Rupture Risk in Patients with Unruptured Intracranial Aneurysms Treated with Endovascular Therapy: A Systematic Review and Meta-Analysis
}

\author{
(D) A. Rizvi, (D) S.M. Seyedsaadat, (D) M. Alzuabi, (D) M.H. Murad, (D) Kadirvel, (D)W. Brinjikji, and (DD.F. Kallmes
}

\begin{abstract}
BACKGROUND: Surveillance imaging of previously unruptured, coiled aneurysms remains routine even though reports of rupture of these aneurysms are extremely rare.

PURPOSE: We performed meta-analysis to examine long-term rupture risk over $\geq 1$-year follow-up duration in patients with unruptured intracranial aneurysm who underwent endovascular therapy.
\end{abstract}

DATA SOURCES: Multiple databases were searched for relevant publications between 1995 and 2018.

STUDY SELECTION: Studies reporting outcome of long-term rupture risk over $\geq$ l-year follow-up in treated patients with unruptured intracranial aneurysms were included.

DATA ANALYSIS: Random effects meta-analysis was used, and results were expressed as long-term rupture rate per 100 patient-year with respective $95 \% \mathrm{Cls}$. For ruptured aneurysms during follow-up, data were collected on size and completeness of initial Treatment.

DATA SYNTHESIS: Twenty-four studies were identified. Among 4842 patients with a mean follow-up duration of 3.2 years, a total of 12 patients $(0.25 \%)$ experienced rupture of previous unruptured intracranial aneurysms after endovascular treatment. Nine of these 12 patients harbored aneurysms that were large, incompletely treated, or both. A total of 2 anterior circulation, small, completely coiled aneurysms subsequently ruptured. The long-term rupture rate per 100 patient-year for unruptured intracranial aneurysms treated with endovascular therapy was $0.48(95 \% \mathrm{Cl}, 0.45-0.51)$. Retreatment was carried out in 236 (4.9\%) of these 4842 patients.

LIMITATIONS: A limitation of the study is that a lack of systematic nature of follow-up and mean follow-up duration of 3.2 years are not sufficient to make general recommendations about aneurysm followup paradigms.

CONCLUSIONS: Given a 5\% retreatment rate, postcoil embolization spontaneous rupture of previously unruptured, small- and medium-sized, well-treated aneurysms is exceedingly rare.

ABBREVIATIONS: $\mathrm{Cl}=$ confidence interval; PRISMA = Preferred Reporting Items for Systematic Reviews and Meta-Analyses; PY = patient-year; UIA = unruptured intracranial aneurysm

$\mathbf{T}$ he advent and popularization of endovascular techniques have led to a growing paradigm shift in coil embolization

Received November 17, 2019; accepted after revision March 19, 2020.

From the Department of Radiology (A.R., S.M.S., M.A., R.K., W.B., D.F.K.) and Evidence-Based Practice Center (M.H.M.), Mayo Clinic, Rochester, Minnesota; Department of Medicine (A.R.), University of Texas Medical Branch, Galveston, Texas; and Joint Department of Medical Imaging (W.B.), Toronto Western Hospital, Toronto, Ontario, Canada.

Grant support: This research was supported by AHA postdoctoral fellowship award \# 19POST34381068 and NIH grant \# NS076491.

Please address correspondence to Asim Rizvi, MD, Department of Radiology, Mayo Clinic, 200 First St SW, Rochester, MN 55905; e-mail: drasimrizvi@gmail.com; @Crabalian

- Indicates open access to non-subscribers at www.ajnr.org

Indicates article with supplemental on-line appendix and tables.

http://dx.doi.org/10.3174/ajnr.A6568 and decline in historical microsurgical clipping techniques for the treatment of unruptured intracranial aneurysms (UIAs) over the past 20 years or so. Multiple studies have emphasized the followup imaging of patients treated with endovascular therapy due to concerns for its long-term durability and increased recurrence rates coupled with greater need for retreatment compared with microsurgical clipping. ${ }^{1-3}$ However, even though recurrences after endovascular therapy are reported in up to $30 \%$ of treated aneurysms, reports of spontaneous rupture of previously unruptured, coiled aneurysms have been unusual. Even though such spontaneous ruptures are rare, most practitioners carry out longterm surveillance imaging and offer retreatment for previously unruptured, coiled aneurysms. ${ }^{4,5}$ Surveillance imaging carries substantial cost and may cause ongoing anxiety, and retreatment 
carries risk of stroke. ${ }^{6}$ Thus, it would benefit the community to better understand the rate of spontaneous rupture of coiled, unruptured aneurysms.

To date, there is lack of randomized controlled trials as well as a paucity of aggregated data regarding rupture risk for both small and large UIAs treated with endovascular techniques. We therefore performed a systematic review and meta-analysis of studies to examine the long-term risk of rupture over a follow-up duration of $\geq 1$ year in patients with UIA who underwent endovascular therapy.

\section{MATERIALS AND METHODS \\ Literature Search}

The current study adheres to PRISMA (Preferred Reporting Items for Systematic Reviews and Meta-Analyses) guidelines. The electronic databases Ovid MEDLINE, Ovid EMBASE, and Scopus were systematically examined to locate relevant studies by using predefined search criteria. The search strategy was designed and conducted by a medical reference librarian with input from the authors. Controlled terminology supplemented with keywords was used to search for unruptured cerebral aneurysm, unruptured brain aneurysm, unruptured intracranial aneurysm AND endovascular treatment of aneurysm, coiling of aneurysm, endovascular coiling, endovascular embolization, elective coil treatment AND long-term follow-up, long-term results, aneurysm rupture, rupture of aneurysm. The search was confined to investigations that were published between January 1995 and December 2018. The search strategy is available in the On-line Appendix.

Three independent investigators scanned all manuscripts and performed data extraction. Abstracts or conference papers were excluded because of insufficient data. All retrieved studies were examined, and any potential overlapping data were omitted. Three reviewers performed the final screening of reports for inclusion in the meta-analysis. In the event of any disagreement, a general consensus was met between reviewers after further extensive review of the full-text articles. In addition, all references cited in the identified articles were manually searched for potentially relevant studies.

\section{Study Eligibility}

The inclusion criteria for studies in the analysis were 1) studies assessing long-term risk of rupture in patients with UIA who underwent endovascular therapy, 2) studies examining previously unruptured small $(<10 \mathrm{~mm})$ and large $(>10 \mathrm{~mm})$ intracranial aneurysms that underwent endovascular treatment, and 3) studies reporting mean follow-up duration of $\geq 1$ year after endovascular therapy. Studies published before 1995 were excluded from this meta-analysis. Studies or patients in the included studies were also excluded if they reported giant $(>25 \mathrm{~mm})$ or ruptured aneurysm at initial presentation. Additionally, animal or in vitro studies as well as studies with $\leq 10$ patients were excluded as were studies published in languages other than English without any available translation.

\section{Data Collection}

Three independent investigators (A.R., S.M.S., and M.A.) extracted data with subsequent verification. The following data were collected for each eligible investigation: year of publication, patient demographics, aneurysm location, mean follow-up duration, and number of patients with ruptures. For documented ruptured aneurysms during follow-up, we collected data on size and completeness of initial treatment (On-line Table 2).

\section{Methodologic Quality}

Because the studies were uncontrolled (case series), the methodologic quality of these series (ie, risk of bias) was analyzed by using a modified tool suggested by Murad et al. ${ }^{7}$ Each study was judged on 5 items categorized into 4 groups: 1) selection bias (whole experience of the treating center, ie, the study reporting consecutive patients at the recruiting center and therefore less likelihood of selective reporting of the patients who had better outcomes), 2) ascertainment bias (ascertainment of exposure and outcome of interest), 3) causality bias (adequate follow-up period for outcomes to occur), and 4) reporting bias (sufficient details to allow for replication of research). For the purposes of the current study, we determined that the risk of bias depended mainly on 2 factors: selection domain and the independent or blinded assessment of outcomes.

\section{Outcome Variables}

For the current study purposes, the following outcome was assessed: long-term rupture of UIA following endovascular treatment over a follow-up duration of $\geq 1$ year.

\section{Statistical Analysis}

From each eligible study, data were extracted for the number of patients with UIA and rupture after endovascular therapy during a follow-up duration of $\geq 1$ year. Event rates were expressed as long-term ( $\geq 1$ year) rupture rate per 100 patient-year (PY) with respective $95 \%$ confidence intervals ( $95 \%$ CIs) that were derived from the Poisson distribution. A continuity correction factor of 0.001 was used to address studies with zero event rates. Random effects meta-analysis was used for pooling across studies. ${ }^{8}$ The $\mathrm{I}^{2}$ statistic was used to express the proportion of heterogeneity that is not attributable to chance. ${ }^{9}$ Meta-analysis was conducted by using STATA Version 15 (StataCorp).

\section{RESULTS}

\section{Literature Search}

We identified 438 articles from the literature search. After removing duplicates, 433 articles were screened by title and abstract. Of these, 122 articles were read full-text. A total of 24 studies met the eligibility criteria and were included in the meta-analysis. A PRISMA flow chart of the search and selection process of the articles is shown in Fig 1.

Baseline characteristics of each study are listed in On-line Table 2. A total of 5309 patients were included who were followed-up for $\geq 1$ year after endovascular therapy. The mean age within studies was $55.0 \pm 6.0$ years, and the mean follow-up duration was 3.2 years. The largest study had 2035 patients, ${ }^{10}$ and the smallest study had 13 patients. ${ }^{11}$ Four studies were multicenter, ${ }^{10,12-14}$ and 20 were single-center studies. ${ }^{11,15-33}$ Among all included studies, the longest mean follow-up duration was 15.5 years, ${ }^{14}$ and the 


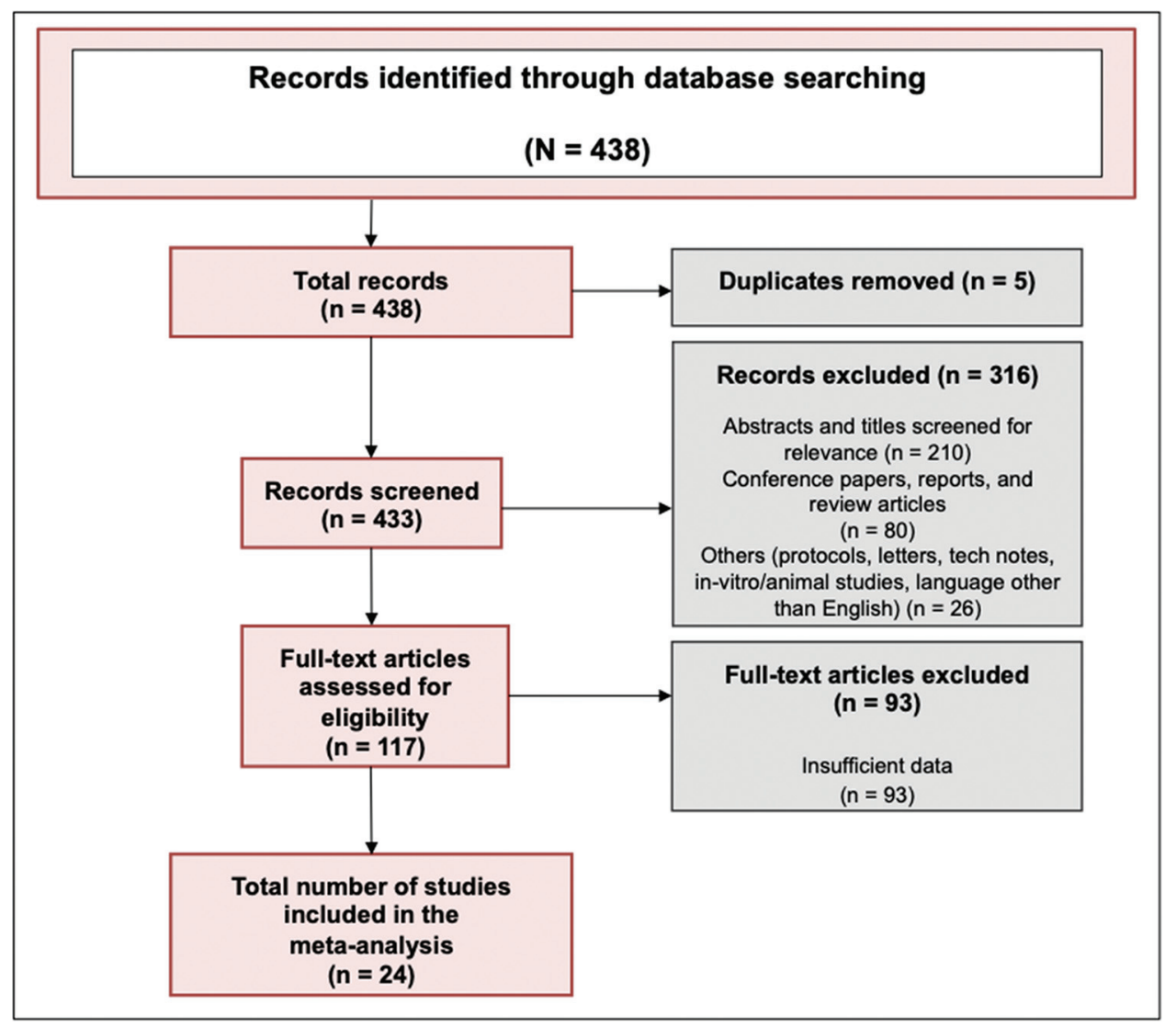

FIG 1. PRISMA (Preferred Reporting Items for Systematic Reviews and Meta-Analyses) flow diagram.

shortest follow-up duration was 1 year. ${ }^{24,27,30}$ Methodologic quality was moderate to high in all included studies (On-line Table 3).

\section{Long-Term Rupture Risk with Unruptured Aneurysms Treated with Endovascular Therapy}

Among 4842 patients with a mean follow-up duration of 3.2 years, a total of 12 patients $(0.25 \%)$ experienced rupture of previously unruptured aneurysms following endovascular treatment. Nine of these 12 patients harbored aneurysms that were either large, incompletely treated, or both. A total of 2 anterior circulation, small, completely coiled aneurysms subsequently ruptured. All these ruptures of previous UIAs were reported more than 1 year after the initial endovascular treatment (Table). The longterm rupture rate per $100 \mathrm{PY}$ for UIAs treated with endovascular therapy was 0.48 (95\% CI, 0.45-0.51) (Fig 2). In particular, $4.9 \%$ of these patients (236 among 4842 patients) underwent retreatments for previously treated UIAs (On-line Table 1).

\section{Heterogeneity}

The $\mathrm{I}^{2}$ value was $98.8 \%$ for long-term rupture rate per $100 \mathrm{PY}$, suggesting high heterogeneity. The low numbers precluded analysis of the reasons for this apparent heterogeneity.

\section{DISCUSSION}

This systematic review and meta-analysis revealed that the subsequent rupture of treated UIAs is extremely unusual and was nearly nonexistent among well-treated, small aneurysms. Overall, we noted that about 1 aneurysm ruptured every $200 \mathrm{PY}$, and most of those few cases represented either small or initially incompletely treated aneurysms. It is potentially notable that the 12 ruptures were spread out over case series published between 1999 and 2018. We fully acknowledge that the true rupture rate of coiled aneurysms remains unknown because about $5 \%$ of the patients in this meta-analysis underwent retreatment. Furthermore, it is plausible that these $5 \%$ were a high-risk group that may have gone on to rupture. We also acknowledge that a mean followup of 3.2 years is not sufficient to make general recommendations about aneurysm surveillance imaging, and a MR angiography every 5 years is not a big request among patients who have a propensity to form life-threatening brain aneurysms. To this end, prior studies have also reported predisposing factors that may predict aneurysm recurrence, which is essentially the biggest risk factor for posttreatment rupture. ${ }^{34}$ Even so, the data contained herein should prompt additional discussion and scrutiny regarding the routine use of surveillance imaging and retreatment in patients with previously treated UIA.

In particular, most reports of rupture of aneurysms previously treated with endovascular therapy were in large, ${ }^{14,20,32}$ suboptimally coiled aneurysms, ${ }^{16,29}$ or both. ${ }^{28}$ Further still, the rates of rupture of UIA may vary widely depending on aneurysm location, size, history of other (ruptured) aneurysms, positive family history, and/or smoking history. The current study brings robust meta-analytic techniques to further underscore the significance of low rupture rates among UIAs 


\begin{tabular}{|c|c|c|c|}
\hline Author, Year & $\begin{array}{l}\text { Number of Patients with } \\
\text { Long-Term Aneurysm } \\
\text { Rupture Posttreatment }\end{array}$ & $\begin{array}{l}\text { Location of Long-Term } \\
\text { Aneurysm Rupture } \\
\text { Posttreatment }\end{array}$ & Reason for Rupture \\
\hline Kaku et al, $1999^{15}$ & 1 & Anterior $(n=1)$ & $\begin{array}{l}\text { Incomplete occlusion followed by aneurysmal } \\
\text { recanalization and regrowth } 15 \text { months after } \\
\text { IDC embolization on carotid angiogram. Patient } \\
\text { had subarachnoid hemorrhage at } 15 \text { months } \\
\text { after treatment and died. }\end{array}$ \\
\hline $\begin{array}{l}\text { Johnston et al, } \\
2000^{16}\end{array}$ & 3 & $\begin{array}{l}\text { Not explicitly reported } \\
\quad(n=3)\end{array}$ & $\begin{array}{l}\text { Rupture caused by incomplete occlusion for } \\
\text { technical reasons leading to delayed } \\
\text { subarachnoid or intracranial hemorrhage during } \\
\text { a mean follow-up duration of } 3.8 \text { years. Two } \\
\text { patients refused follow-up angiography despite } \\
\text { new compressive symptoms. In the third } \\
\text { patient, only a small portion of the aneurysm } \\
\text { could be treated, and surgical clipping was } \\
\text { refused. }\end{array}$ \\
\hline Terada et al, $2005^{20}$ & 1 & Posterior $(n=1)$ & $\begin{array}{l}\text { Bilateral posterior cerebral arteries were left } \\
\text { patent after aneurysm embolization. Fatal } \\
\text { rupture of large basilar tip aneurysm at } 28 \\
\text { months due to no follow-up visits and died the } \\
\text { day before admission from a massive } \\
\text { subarachnoid hemorrhage. }\end{array}$ \\
\hline Im et al, $2009^{12}$ & 1 & Anterior $(n=1)$ & $\begin{array}{l}\text { Rupture occurred } 18 \text { months after complete coil } \\
\text { embolization of a 5-mm MCA bifurcation } \\
\text { aneurysm. The patient was lost to clinical } \\
\text { follow-up after initial coil embolization, which } \\
\text { was later on completely occluded by second } \\
\text { coil embolization. The patient had a good } \\
\text { recovery without neurologic deficits. }\end{array}$ \\
\hline Pyysalo et al, $2013^{28}$ & 3 & $\begin{array}{l}\text { Anterior }(n=2) \\
\text { Not explicitly reported } \\
\quad(n=1)\end{array}$ & $\begin{array}{l}\text { Delayed ruptures during mean follow-up duration } \\
\text { of } 13 \text { years. First patient with 20-mm, } \\
\text { incompletely coiled MCA aneurysm with no } \\
\text { follow-up due to age of } 65 \text { years. Second } \\
\text { patient with 4-mm, completely coiled MCA } \\
\text { aneurysm with some follow-up and rupture a } \\
\text { couple of years later. The data were not found } \\
\text { for the third patient. }\end{array}$ \\
\hline Mine et al, $2014^{29}$ & 1 & $\begin{array}{l}\text { Not explicitly reported } \\
\qquad(n=1)\end{array}$ & $\begin{array}{l}\text { Delayed rupture during mean follow-up duration } \\
\text { of } 2.2 \text { years because of incomplete coiling and } \\
\text { refusal of further treatment. }\end{array}$ \\
\hline Petr et al, $2016^{32}$ & 1 & Anterior $(n=1)$ & $\begin{array}{l}\text { Delayed rupture of large MCA aneurysm and } \\
\text { death during a mean follow-up duration of } 1.7 \\
\text { years. }\end{array}$ \\
\hline Koyanagi et al, $2018^{14}$ & 1 & Posterior $(n=1)$ & $\begin{array}{l}\text { Rupture of a large (14-mm) basilar bifurcation } \\
\text { aneurysm at } 21 \text { months. }\end{array}$ \\
\hline Total & 12 & & \\
\hline
\end{tabular}

Note:-IDC indicates interlocking detachable coils.

previously treated by endovascular therapy and represents a systematic aggregation of long-term rupture rate after endovascular therapy during a follow-up duration of $\geq 1$ year. It extends the findings of smaller studies, which may be limited by factors such as small sample size or single-center design, and it broadens generalizability.

The extremely low rate of posttreatment rupture is not at all surprising, given the low rates of spontaneous rupture of untreated UIA. Based on outcomes from ruptured aneurysm case series, it is clear that coil embolization is highly protective of rerupture, diminishing rerupture rates from about $50 \%$ for untreated aneurysms to $<2 \%$ for coiled aneurysms. A similar relative decrease in rupture rate for UIA would bring down an already low rate to a vanishingly low rate, rendering routine surveillance imaging, at least in small, completely coiled aneurysms, potentially unnecessary. Our study carried out a complete analysis of the best existing data on rupture of previously unruptured, coiled aneurysms and has shown that rupture is extremely rare. It will hopefully prompt future researchers to catalog all relevant data, including reasons for retreatment, in future publications. We acknowledge that noninvasive imaging with MR angiography at extended intervals would not be unreasonable until further data are available.

This study has limitations. There was lack of a systematic nature of follow-up among included studies with imaging modalities such as digital subtraction angiography and MR angiography. We were unable to stratify outcome of long-term rupture by size of 


\begin{tabular}{|c|c|}
\hline $\begin{array}{l}\text { Author, } \\
\text { year }\end{array}$ & $\begin{array}{l}\text { Rate Per } \\
100-\mathrm{PY}(95 \% \mathrm{Cl})\end{array}$ \\
\hline Kaku et al, 1999 & $1.70(1.38,2.07)$ \\
\hline Johnston et al, 2000 & $1.93(1.71,2.16)$ \\
\hline Roy et al, 2001 & $0.00(0.00,0.01)$ \\
\hline Wanke et al, 2002 & $0.00(0.00,0.06)$ \\
\hline Ross et al, 2005 & $0.00(0.00,0.05)$ \\
\hline Terada et al, 2005 & $0.41(0.33,0.50)$ \\
\hline Park et al, 2008 & $0.00(0.00,0.06)$ \\
\hline Standhardt et al, 2008 & $0.00(0.00,0.01)$ \\
\hline IM et al, 2009 & $0.15(0.12,0.18)$ \\
\hline Bandeira et al, 2010 & $0.00(0.00,0.01)$ \\
\hline White et al, 2011 & $0.00(0.00,0.01)$ \\
\hline Jang et al, 2011 & $0.00(0.00,0.15)$ \\
\hline Maldonado et al, 2011 & $0.00(0.00,0.03)$ \\
\hline Oishi et al, 2012 & $0.00(0.00,0.00)$ \\
\hline Fields et al, 2013 & $0.00(0.00,0.19)$ \\
\hline Pyysalo et al, 2013 & $0.41(0.37,0.46)$ \\
\hline Mine et al, 2014 & $0.28(0.23,0.34)$ \\
\hline Kwon et al, 2014 & $0.00(0.00,0.00)$ \\
\hline Poncyljusz et al, 2015 & $0.00(0.00,0.04)$ \\
\hline Starke et al, 2015 & $0.00(0.00,0.01)$ \\
\hline Zhu et al, 2015 & $0.00(0.00,0.12)$ \\
\hline Petr et al, 2016 & $0.31(0.25,0.38)$ \\
\hline Koyanagi et al, 2018 & $0.04(0.03,0.04)$ \\
\hline Sedat et al, 2018 & $0.00(0.00,0.01)$ \\
\hline Overall $(\mathrm{I}$-squared $=98.8 \%, p=0.000)$ & $0.48(0.45,0.51)$ \\
\hline .01 & \\
\hline
\end{tabular}

FIG 2. Forest plot for long-term ( $\geq 1$ year) rupture rate per 100 patient-year (PY) with respective $95 \%$ confidence intervals ( $95 \% \mathrm{Cls})$.

aneurysms because specific data from most of the studies cannot be used because of a lack of detailed information for statistical analysis purposes. Additionally, a mean follow-up duration of 3.2 years is not sufficient to make general recommendations about aneurysm follow-up paradigms. As noted, about 5\% of aneurysms underwent retreatment, so we cannot exclude the possibility that some of these retreated aneurysms would have gone on to rupture without retreatment. Further still, specific reasons for retreatment were not provided in the available studies, though we can surmise that recanalization likely was the most common cause. For this reason, our study can be best applied in the setting of patients who were not subsequently retreated, for any reason, which remains most patients. There is a lack of a core laboratory and lack of standardization in reporting specific data, such as size criteria defining an aneurysm as "large," what constitutes a suboptimally coiled aneurysm, or even agreement in how to measure a complex-shaped aneurysm. Furthermore, variability exists in the type (MR angiography vs digital subtraction angiography) and intervals of surveillance imaging. Techniques and technology also dramatically changed during the study period, which may affect results, as well as the applicability of the practices and rupture rate in the 1990s to today's practices and surveillance philosophies. We also acknowledge that correlation of rupture with myriad demographic features would be instructive. However, the vanishingly rare event rate (12 cases among almost 5000 aneurysms) renders any such subanalysis or correlative study impossible. Another limitation is that particularly in large metropolitan medical centers, the ability to reliably track for subsequent hemorrhage may be susceptible to underreporting, and given that this is a literature review, we do not have access to systematic databases such as the Veterans Affairs system. Last, this review includes studies of various designs, each of which may have its own set of limitations.

\section{CONCLUSIONS}

Given a 5\% retreatment rate, post-coil embolization spontaneous rupture of previously unruptured, small- and medium-sized, well-treated aneurysms is exceedingly rare. Future studies are warranted with complete follow-up reporting to address the basic question about the risk of hemorrhage.

Disclosures: Asim Rizvi—RELATED: Grant: 19POST34381068, Comments: American Heart Association Grant, AHA postdoctoral fellowship award*; Support for Travel to Meetings for the Study or Other Purposes: 19POST34381068, Comments: American Heart Association Grant, AHA postdoctoral fellowship award*; Other: NS076491, Comments: NIH grant*; UNRELATED: Grants/Grants Pending: 19POST34381068, Comments: This research was supported by AHA postdoctoral fellowship award \# 19POST34381068 and NIH grant \# NS076491.* Seyed Mohammad 
Seyedsaadat-RELATED: Grant: AHA 2 years postdoctoral research fellowship. Ram Kadirvel-RELATED: Grant: NIH, Comments: R01 NS076491 and R43 NS110114; Other: Cerenovus, Insera Therapeutics LLC, Marblehead Medical LLC, Microvention Inc, MIVI Neuroscience Inc, Neurogami Medical Inc, Triticum Inc, Comments: Research contracts; UNRELATED: Stock/Stock Options: Neurosigma Inc.* David KallmesUNRELATED: Grants/Grants Pending: Medtronic, Microvention, NeuroSigma, Neurogami, General Electric, Comments: Research support*; Stock/Stock Options: Superior Medical Experts, Comments: Founder/stockholder. *Money paid to institution.

\section{REFERENCES}

1. Byrne JV, Sohn MJ, Molyneux AJ, et al. Five-year experience in using coil embolization for ruptured intracranial aneurysms: outcomes and incidence of late rebleeding. J Neurosurg 1999;90:656-63 CrossRef Medline

2. Campi A, Ramzi N, Molyneux AJ, et al. Retreatment of ruptured cerebral aneurysms in patients randomized by coiling or clipping in the International Subarachnoid Aneurysm Trial (ISAT). Stroke 2007;38:1538-44 CrossRef

3. Plowman RS, Clarke A, Clarke M, et al. Sixteen-year single-surgeon experience with coil embolization for ruptured intracranial aneurysms: recurrence rates and incidence of late rebleeding. Clinical article. J Neurosurg 2011;114:863-74 CrossRef Medline

4. Soize S, Gawlitza M, Raoult $\mathrm{H}$, et al. Imaging follow-up of intracranial aneurysms treated by endovascular means: why, when, and how? Stroke 2016;47:1407-12 CrossRef Medline

5. Wallace RC, Karis JP, Partovi S, et al. Noninvasive imaging of treated cerebral aneurysms, part I: MR angiographic follow-up of coiled aneurysms. AJNR Am J Neuroradiol 2007;28:1001-18 CrossRef Medline

6. Thompson BG, Brown RD, Amin-Hanjani S, et al; American Heart Association Stroke Council, Council on Cardiovascular and Stroke Nursing, and Council on Epidemiology and Prevention; American Heart Association; American Stroke Association. Guidelines for the Management of Patients With Unruptured Intracranial Aneurysms: A Guideline for Healthcare Professionals From the American Heart Association/American Stroke Association. Stroke 2015;46:2368-400 CrossRef Medline

7. Murad MH, Sultan S, Haffar S, et al. Methodological quality and synthesis of case series and case reports. BMJ Evid Based Med 2018;23:60-63 CrossRef Medline

8. DerSimonian R, Laird N. Meta-analysis in clinical trials. Control Clin Trials 1986;7:177-88 CrossRef

9. Higgins JP, Thompson SG, Deeks JJ, et al. Measuring inconsistency in meta-analyses. BMJ 2003;327:557-60 CrossRef Medline

10. Kwon SC, Kwon O-K; Korean Unruptured Cerebral Aneurysm Coiling (KUCAC) Investigators. Endovascular coil embolization of unruptured intracranial aneurysms: a Korean multicenter study. Acta Neurochir (Wien) 2014;156:847-54 CrossRef Medline

11. Zhu Y, Pan J, Shen J, et al. Clinical and radiological outcomes after treatment of unruptured paraophthalmic internal carotid artery aneurysms: a comparative and pooled analysis of single-center experiences. World Neurosurg 2015;84:1726-38 CrossRef

12. Im SH, Han MH, Kwon OK, et al. Endovascular coil embolization of 435 small asymptomatic unruptured intracranial aneurysms: procedural morbidity and patient outcome. AJNR Am J Neuroradiol 2009;30:79-84 CrossRef

13. White PM, Lewis SC, Gholkar A, et al; HELPS trial collaborators. Hydrogel-coated coils versus bare platinum coils for the endovascular treatment of intracranial aneurysms (HELPS): a randomised controlled trial. Lancet 2011;377:1655-62 CrossRef Medline

14. Koyanagi M, Ishii A, Imamura H, et al. Long-term outcomes of coil embolization of unruptured intracranial aneurysms. J Neurosurg 2018;129:1492-98 CrossRef Medline

15. Kaku Y, Yoshimura S, Hayashi K, et al. Follow-up study on intraaneurysmal embolization for unruptured cerebral aneurysms. Interv Neuroradiol 1999;5(suppl 5):89-92 CrossRef Medline
16. Johnston SC, Wilson CB, Halbach VV, et al. Endovascular and surgical treatment of unruptured cerebral aneurysms: comparison of risks. Ann Neurol 2000;48:11-19 CrossRef

17. Roy D, Milot G, Raymond J. Endovascular treatment of unruptured aneurysms. Stroke 2001;32:1998-2004 CrossRef Medline

18. Wanke I, Doerfler A, Dietrich U, et al. Endovascular treatment of unruptured intracranial aneurysms. AJNR Am J Neuroradiol 2002;23:756-61

19. Ross IB, Dhillon GS. Complications of endovascular treatment of cerebral aneurysms. Surg Neurol 2005;64:12-18 discussion 18-19 CrossRef Medline

20. Terada T, Tsuura M, Matsumoto H, et al. Endovascular treatment of unruptured cerebral aneurysms. Acta Neurochir Suppl 2005;94:8791 CrossRef Medline

21. Park SH, Lee CY, Yim MB. The merits of endovascular coil surgery for patients with unruptured intracranial aneurysms. J Korean Neurosurg Soc 2008;43:270-74 CrossRef Medline

22. Standhardt H, Boecher-Schwarz H, Gruber A, et al. Endovascular treatment of unruptured intracranial aneurysms with Guglielmi detachable coils: short- and long-term results of a single-centre series. Stroke 2008;39:899-904 CrossRef Medline

23. Bandeira A, Raphaeli G, Baleriaux D, et al. Selective embolization of unruptured intracranial aneurysms is associated with low retreatment rate. Neuroradiology 2010;52:141-46 CrossRef

24. Jang EW, Jung JY, Hong CK, et al. Benefits of surgical treatment for unruptured intracranial aneurysms in elderly patients. $J$ Korean Neurosurg Soc 2011;49:20-25 CrossRef Medline

25. Maldonado IL, Machi P, Costalat V, et al. Neuroform stent-assisted coiling of unruptured intracranial aneurysms: short- and midterm results from a single-center experience with 68 patients. AJNR Am J Neuroradiol 2011;32:131-36 CrossRef Medline

26. Oishi H, Yamamoto M, Shimizu T, et al. Endovascular therapy of 500 small asymptomatic unruptured intracranial aneurysms. AJNR Am J Neuroradiol 2012;33:958-64 CrossRef

27. Fields JD, Brambrink L, Dogan A, et al. Stent assisted coil embolization of unruptured middle cerebral artery aneurysms. $J$ NeuroIntervent Surg 2013;5:15-19 CrossRef

28. Pyysalo L, Luostarinen T, Keski-Nisula L, et al. Long-term excess mortality of patients with treated and untreated unruptured intracranial aneurysms. J Neurol Neurosurg Psychiatry 2013;84:888-92 CrossRef Medline

29. Mine B, Aljishi A, D'Harcour J-B, et al. Stent-assisted coiling of unruptured intracranial aneurysms: long-term follow-up in 164 patients with 183 aneurysms. J Neuroradiol 2014;41:322-28 CrossRef Medline

30. Poncyljusz W, Zarzycki A, Zwarzany L, et al. Bare platinum coils vs. HydroCoil in the treatment of unruptured intracranial aneurysms-a single center randomized controlled study. Eur J Radiology 2015;84:261-65 CrossRef Medline

31. Starke RM, Durst CR, Evans A, et al. Endovascular treatment of unruptured wide-necked intracranial aneurysms: comparison of dual microcatheter technique and stent-assisted coil embolization. J Neurointerv Surg 2015;7:256-61 CrossRef Medline

32. Petr O, Brinjikji W, Cloft $\mathrm{H}$, et al. Current trends and results of endovascular treatment of unruptured intracranial aneurysms at a single institution in the flow-diverter era. AJNR Am J Neuroradiol 2016;37:1106-13 CrossRef

33. Sedat J, Chau Y, Gaudart J, et al. Stent-assisted coiling of intracranial aneurysms using LEO stents: long-term follow-up in 153 patients. Neuroradiology 2018;60:211-19 CrossRef Medline

34. Zhang Q, Jing L, Liu J, et al. Predisposing factors for recanalization of cerebral aneurysms after endovascular embolization: a multivariate study. J Neurointerv Surg 2018;10:252-57 CrossRef Medline 